\title{
Magnetron sputtering technique for analyzing the influence of RF sputtering power on microstructural surface morphology of aluminum thin films deposited on $\mathrm{SiO}_{2} / \mathrm{Si}$ substrates
}

\author{
Somayeh Asgary ${ }^{1}$. Elnaz Vaghri ${ }^{2}$ - Masoumeh Daemi ${ }^{3}$. Parisa Esmaili ${ }^{4} \cdot$ Amir H. Ramezani $^{1}$. Saim Memon ${ }^{5}$. \\ Siamak Hoseinzadeh ${ }^{6} \mathbb{D}$
}

Received: 8 July 2021 / Accepted: 29 August 2021 / Published online: 10 September 2021

(c) The Author(s) 2021

\begin{abstract}
In this research, aluminum (Al) thin films were deposited on $\mathrm{SiO}_{2} / \mathrm{Si}$ substrates using $\mathrm{RF}$ magnetron sputtering technique for analyzing the influence of RF sputtering power on microstructural surface morphologies. Different sputtering RF powers $(100-400 \mathrm{~W})$ were employed to form Al thin films. The characteristics of deposited Al thin films are investigated using X-ray diffraction pattern (XRD), scanning electron microscopy (SEM), atomic force microscopy (AFM) and Fourier-transforms infrared (FTIR) spectroscopy. The X-ray diffraction (XRD) results demonstrate that the deposited films in low sputtering power have amorphous nature. By increasing the sputtering power, crystallization is observed. AFM analysis results show that the RF power of $300 \mathrm{~W}$ is the optimum sputtering power to grow the smoothest Al thin films. FTIR results show that the varying RF power affect the chemical structure of the deposited films. The SEM results show that by increasing the sputtering power leads to the formation of isolated texture on the surface of substrate. In conclusion, RF power has a significant impact on the properties of deposited films, particularly crystallization and shape.
\end{abstract}

Keywords Aluminum thin films · Grain size $\cdot$ Magnetron sputtering $\cdot$ RF power $\cdot$ FTIR

\section{Introduction}

Aluminum (Al) thin films are widely used in optical and microelectronic applications. These thin films have attracted a considerable attention in both academic and industrial

Siamak Hoseinzadeh

siamak.hosseinzadeh@uniroma1.it

1 Department of Physics, West Tehran Branch, Islamic Azad University, Tehran, Iran

2 Young Researchers and Elite Club, Shahr-E-Qods Branch, Islamic Azad University, Tehran, Iran

3 Department of Physics, Urmia branch, Islamic Azad University, Urmia, Iran

4 Young Researchers and Elite Club, Urmia branch, Islamic Azad University, Urmia, Iran

5 Solar Thermal Vacuum Engineering Research Group, School of Engineering, London Centre for Energy Engineering, London South Bank University, London SE1 0AA, UK

6 Department of Planning, Design, Technology, Sapienza University of Rome, Via Flaminia 72, 00196 Rome, Italy communities due to their remarkable properties and characteristics such as high reflectance, low resistivity, high conductance, better adhesion, resistance to oxidation and corrosion [1, 2] and novel optical properties [3, 4]. A significant scope of the Al thin films and tungsten oxide thin films $[5,6]$, specifically in the formation of composite for industrial aircraft applications. Recently, the optimum dielectric performance of polymer nanocomposites and improvement of the mixed conductivities have been explored by [7, 8] Due to these outstanding properties, $\mathrm{Al}$ thin films find wide applications can also be in microelectronics systems, semiconductors and optics components [2]. Furthermore, the interest in $\mathrm{Al}$ thin films has been exponentially increased due to depositions have been achieved utilizing a broad spectrum of substrates including mild steels, titanium, stainless steel, silver, silicon (100), polyethylene terephthalate (PET), polycarbonates and glass [2, 9]. Al films deposited on substrates are the most commonly utilizes surface coatings for aspheric mirrors, because $\mathrm{Al}$ is a good light reflector in the visible region and an extraordinary reflector in the mid and far infrared (IR) regions [10, 11]. In addition, other applications of $\mathrm{Al}$ thin films in different industrial fields include thin 
film transistors [12], near-field fiber-optic probes [13], solar cells [14] and flat-panel displays [15].

$\mathrm{Al}$ thin films can be synthesized by various methods such as evaporation and sputtering, which can employ either thermal or electron beam sources [16, 17]. In general, sputter deposition is more suitable for materials with higher melting points, which are difficult to evaporate.

Among these methods, sputtering has attracted a great deal of interest due to its many concurrent advantages like; low substrate temperature, ability to produce reasonable quality thin films at a high deposition rate, good surface roughness and low cost $[18,19]$. This technique has several advantages, including excellent control of film thickness, the fabrication of high-density film and high-quality aluminum oxide films. This technique allows precise control of purity, composition and stoichiometry of the films.

It is well known that the deposition conditions such as substrate temperature, deposition rates, sputtering power, substrate type and bias voltage have effects on the properties of thin films $[2,20]$. In the past few years, many experimental studies were focused on the effects of sputtering RF power on the characteristics of the deposited films. For example; Dhar et al. have analyzed the effect of sputtering power, operating pressure and deposition temperature on the properties of Mo thin films grown on Mo sheet and soda-lime glass (SLG) [21]. Mahdhi et al. have investigated the influence of sputtering power on the properties of thin layers of GZO for photovoltaic applications [22]. Murugan et al. have performed studies about the effect of RF power on the properties of magnetron sputtered $\mathrm{CeO}_{2}$ thin films [23, 24]. Zhao et al. have studied on effects of power on properties of $\mathrm{ZnO}$ thin films grown by radio frequency magnetron sputtering [25].

Even though extensive research has been carried out on the effects of RF power on the characteristics of various deposited films, there are very scarce works focused on the effect of sputtering power on the characteristic of the sputtered $\mathrm{Al}$ thin films. The novelty of this research is the experimental investigation the microstructure characteristics, roughness and optical properties of $\mathrm{Al}$ thin films deposited by RF sputtering at varying powers of $100 \mathrm{~W}, 200 \mathrm{~W}, 300 \mathrm{~W}$ and $400 \mathrm{~W}$ at a substrate temperature of $150{ }^{\circ} \mathrm{C}$.

\section{Experimental methodology}

Al thin films were deposited using RF magnetron sputtering setup on $\mathrm{SiO}_{2} / \mathrm{Si}$ substrates with an $\mathrm{Al}$ target (purity of 99.9999\%). All the substrates were cleaned ultrasonically in acetone, isopropanol and deionized (DI) water for $15 \mathrm{~min}$, respectively, to remove any residual contaminants prior to deposition.
The samples introduced into the RF sputtering chamber and then it was pumped to high vacuum pressure of 8.6 Torr $\times 10^{-6}\left(1.14 \mathrm{~Pa} \times 10^{-3}\right)$ achieved with rotary pump and turbomolecular pump. Argon gas (inert gas) was purged into the chamber with a flow of $3 \mathrm{sccm}$ for sputtering process. The distance between the target and the substrate in our experimental condition was $\approx 7 \mathrm{~cm}$. The $\mathrm{Al}$ target was pre-sputtered for $10 \mathrm{~min}$ to decontaminate and remove impurities before performing the depositions. Al thin films were deposited on the $\mathrm{SiO}_{2} / \mathrm{Si}$ substrates at different sputtering powers from 100 to $400 \mathrm{~W}$ by maintaining other deposition conditions. The details of the sputtering conditions during the deposited of Al films are given in Table 1.

The generated samples were characterized using a range of analytical methods. The crystal structures of the deposited films were analyzed using a $\mathrm{Cu}-\mathrm{Ka}$ radiation $\left(k=1.54060 \mathrm{~A}^{\circ}\right)$ of STOE SIADI MP diffractometer. The surface morphology of the samples was investigated by Hitachi, S-3400 emission scanning electron microscopy (SEM). Fourier-transforms infrared (FTIR) spectroscopy with a PerkinElmer spectrometer at a resolution of $8 \mathrm{~cm}^{-1}$ in the range of $500-3800 \mathrm{~cm}^{-1}$ was employed to investigate the bonding structures of the deposited samples. The topography of the surface and roughness of the deposited films were investigated by atomic force microscopy (AFM) (Dual Scope TM DS) analysis.

\section{Result and discussion}

\subsection{X-Ray diffraction analysis (XRD)}

The X-ray diffraction patterns of the films deposited on $\mathrm{SiO}_{2} / \mathrm{Si}$ substrates, at different RF powers are shown in Fig. 1. In Fig. 1(a) and (b) labels show low sputtering powers of $100 \mathrm{~W}$ and $200 \mathrm{~W}$, respectively, there was no peak in their XRD pattern and the deposited films indicate noncrystalline feature. As the sputtering power increases to 300 leading to $400 \mathrm{~W}$, new diffraction peaks at $2 \theta=30.9^{\circ}$ and $2 \theta=61.6^{\circ}$ corresponding to (001) and (430) reflection planes of orthorhombic aluminum silicone oxide structure (JCPDS card No. 002-0428 and 002-0469) observed in the

Table 1 List of the deposition parameters utilized to deposit the $\mathrm{Al}$ thin films on $\mathrm{SiO}_{2} / \mathrm{Si}$ substrate

\begin{tabular}{ll}
\hline Process parameters & Value \\
\hline Target to substrate distance $(\mathrm{cm})$ & 7 \\
RF power $(\mathrm{W})$ & $100-400$ \\
Substrate temperature $\left({ }^{\circ} \mathrm{C}\right)$ & 150 \\
Base pressure (Torr) & $8.6 \times 10^{-6}$ \\
Deposition time & $15($ minute $)$ \\
Working pressure (Torr) & $9 \times 10^{-4}$ \\
\hline
\end{tabular}




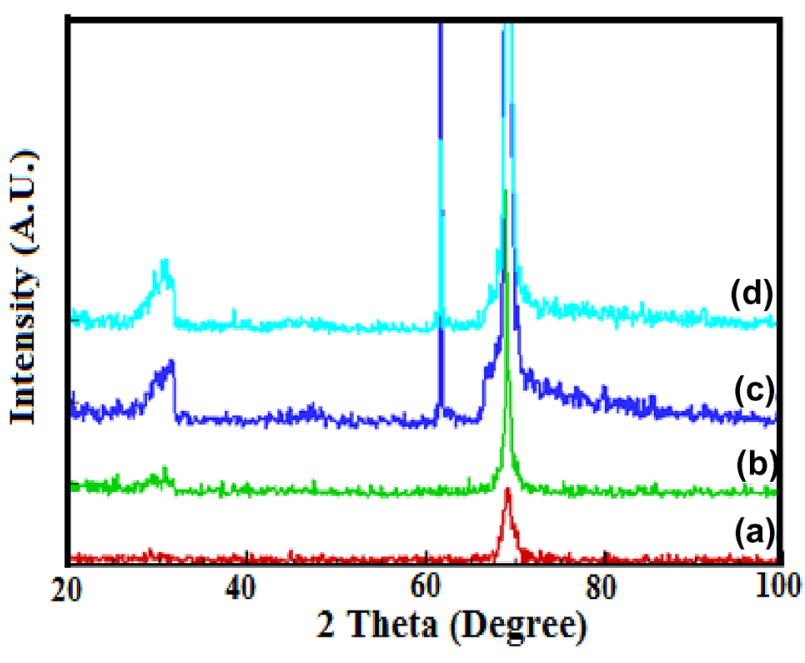

Fig.1 X-ray diffraction pattern of the $\mathrm{Al}$ thin films deposited on $\mathrm{SiO}_{2} /$ Si substrate at different RF powers of shown in label (a) $100 \mathrm{~W}$, (b) $200 \mathrm{~W}$, (c) $300 \mathrm{~W}$ and (d) 400

XRD pattern of the deposited films, as shown in Fig. 1, label (a) and (b). Furthermore, in Fig. 1 label (c) shows the peak at $2 \theta=80.01^{\circ}$ also attributed to X-ray photons diffracted from aluminum silicone oxide structure (JCPDS card No. 002-0413). The appearance of these diffraction peaks at higher sputtering powers may be attributed to surface diffusion of $\mathrm{Al}$ sputtered atoms on the substrate. It seems that higher RF power enhanced mobility energy of Al sputtered atoms on the surface of the substrate to diffuse in the substrate during growth stage and formed a new phase of aluminum silicone oxide. In other word, higher sputtering power induced high incident ion energy, resulting in high surface mobility and mean diffusion path of sputtered atoms [26]. In addition, X-ray diffraction pattern, Fig. 1 label (d) exhibits a weak diffraction peak around $38.3^{\circ}$ belongs to the (111) reflection planes of aluminum structure (JCPDS card No. 004-0787). Moreover, a peak of X-ray photons diffracted (111) planes of Si substrate lattice structure can be seen a $2 \theta=69.6^{\circ}$. Increasing the intensity of diffraction peaks by increasing the RF power confirms a better crystallinity of the samples at higher RF powers. By increasing the sputtering power, the sputtering yield becomes high and the sputtered particles are ejected with higher energy and the growth of a more crystallized phase [26]. It seems that the peak at $2 \theta=61.6^{\circ}$ is the preferred crystalline orientation in higher RF power and is so strong in $300 \mathrm{~W}$.

\subsection{Surface morphological analysis}

\subsubsection{Surface roughness}

The surface roughness was analyzed using atomic force microscopy (AFM) in contact mode for all samples. Figure 2 illustrates the three-dimensional-AFM micrographs of the $\mathrm{Al}$
Fig. 2 3D AFM images of $\mathrm{Al}$ films deposited on $\mathrm{SiO}_{2} / \mathrm{Si}$ substrate at various sputtering powers: a $100 \mathrm{~W}$, b $200 \mathrm{~W}$, c $300 \mathrm{~W}$ and $\mathbf{d} 400 \mathrm{~W}$
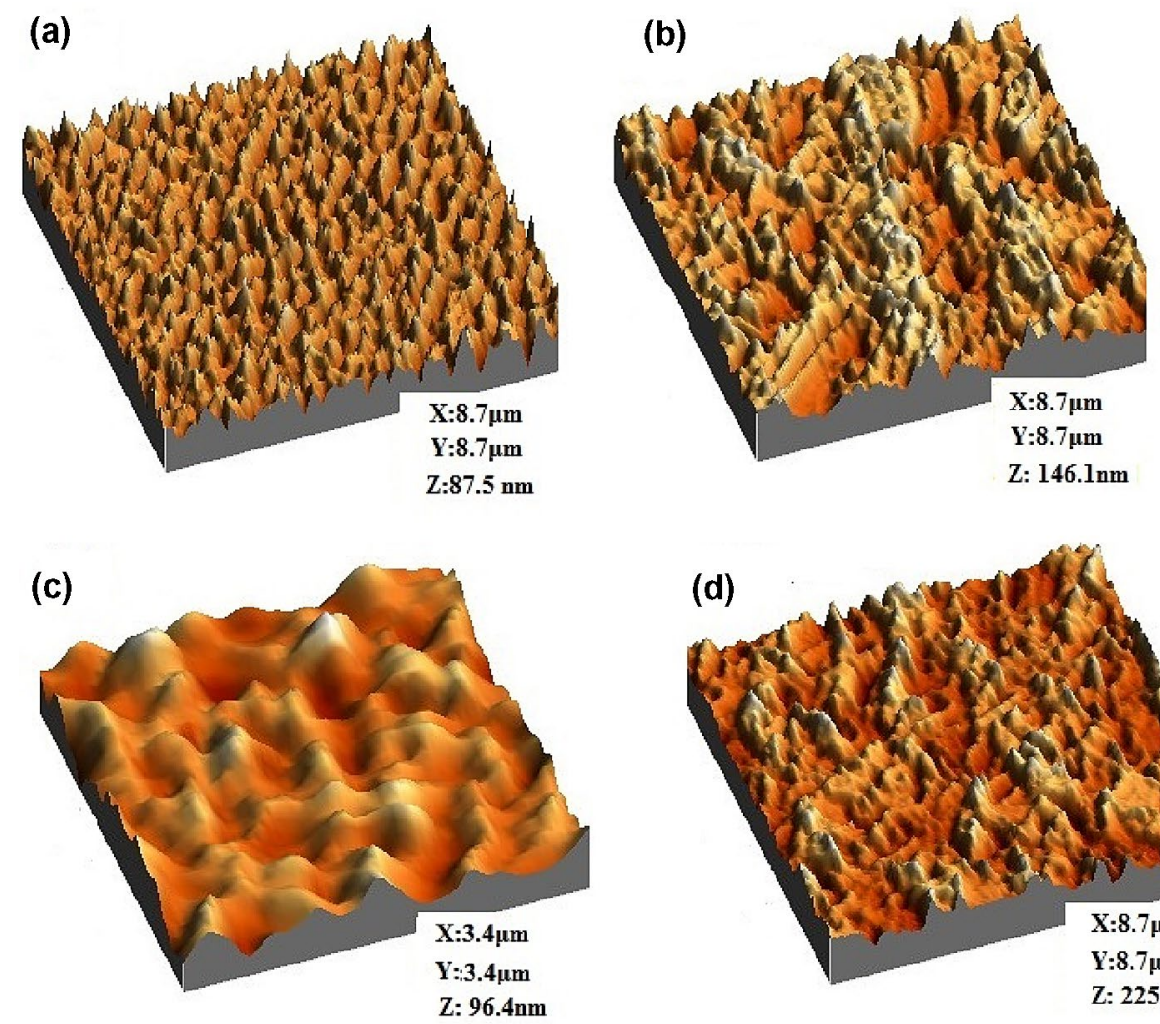

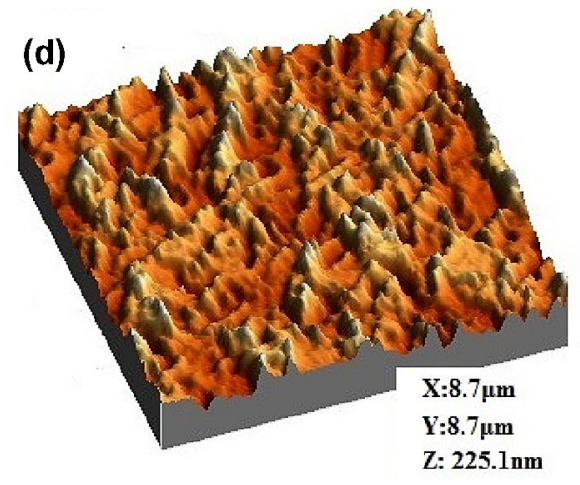


films deposited at different sputtering powers. The root mean squared (RMS) roughness of surface is the main parameters for the characterization of the surface structure [27, 28].

$\mathrm{RMS}=\sqrt{\frac{\sum_{\mathrm{n}=1}^{\mathrm{N}}\left(\mathrm{Z}_{\mathrm{n}}-\overline{\mathrm{Z}}\right)^{2}}{\mathrm{~N}-1}}$

where $\bar{Z}$ is the average height and $N$ is the number of data points. The roughness of the films deposited at different RF powers is plotted in Fig. 3. The RMS roughness of the asdeposited film initially rose to $16.95 \mathrm{~nm}$ when the sputtering power was raised to $200 \mathrm{~W}$, as shown in Fig. 3. Thereafter, it decreased to $12.16 \mathrm{~nm}$ when the deposition increased to $300 \mathrm{~W}$. This behavior may be explained in the following way: (i) At a low RF power of $200 \mathrm{~W}$, the atoms or ions have low energy and tended to 'stay' at the site of its arrival, thus creating a much rougher surface [26, 29]; (ii) At a high RF power of $300 \mathrm{~W}$, the kinetic energy of the incoming atoms, particles or ions, increases that enhances the lateral diffusion of the ions or particles, and then the surface roughness decreases. Moreover, it was discovered that as the RF power was increased to $400 \mathrm{~W}$, the roughness increased. This may be attributed to the fact that the higher power improved the energy of the incoming ionized species and decreased the rearrangement time of the atoms on the substrate before arrival of next atoms [29, 30], which thereby resulted in higher surface roughness [26].

At high RF power, the argon gas and the deposition particles inside the sputtering chamber acquire very kinetic high energy, which may lead to: (i) high deposition rate, growth and recrystallization leading to large grain sizes, (ii) excess collisions between target atoms and ions reducing

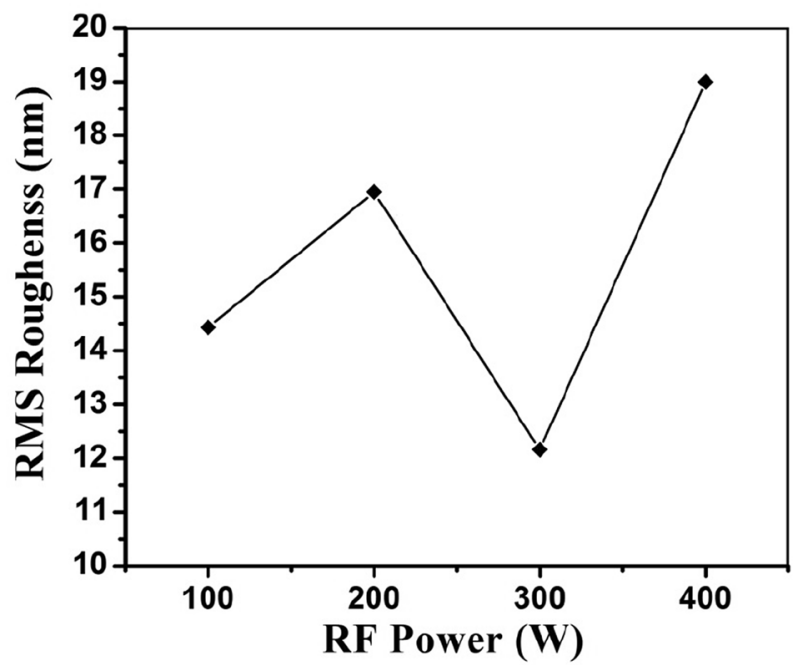

Fig. 3 The RMS roughness of $\mathrm{Al}$ thin films deposited on $\mathrm{SiO}_{2} / \mathrm{Si}$ substrate as a function of sputtered RF power the mean-free-path of the target atoms and therefore lowering sputtering yield and hence less crystallization and film growth [31, 32]. The results presented in sample 2 and 4 can well be attributed to the first reason.

Although the RMS values are highly influenced by the RF power, our result shows that there exists no direct correlation between the increase in RF power and RMS values. The finest and well-defined grained microstructure was observed at the power of $300 \mathrm{~W}$ and the highest RMS roughness values are obtained on the surface of films sputtered at a power of $400 \mathrm{~W}$. According to our study, the RF power of $300 \mathrm{~W}$ is the optimum condition for deposition of Al thin film.

\subsubsection{Scanning electron microscopy analysis (SEM)}

Figure 4 illustrates the SEM micrographs of the deposited films showing, at lower RF powers, the deposited films are composed of small, homogenous and well-defined grains. In addition, interconnected porous structures between the grains were observed. The presence of these porous structures is attributed to the high roughness values. The SEM images indicate that with an increase of RF power led to the growth of larger grains. In fact, with increasing sputtering RF power, the deposition particles did not have enough time to latterly diffuse on the substrate, and accumulated together to form larger grains [26]. This result is in good agreement with the results of AFM analysis.

\subsubsection{FT-IR characterization}

The Fourier-transformed infrared spectroscopy (FT-IR) is an analytical technique which is used to investigate the chemical structure and molecular bonding of the materials. The infrared spectra of the produced samples in the range of 500-3800 $\mathrm{cm}^{-1}$ are depicted in Fig. 5. In the lower frequency region, the minor absorption peak (low intensity) appearing at around $619 \mathrm{~cm}^{-1}$ can be assigned to a coupled Al-O and Si-O (out-of-plane) bond [33, 34]. Furthermore, the absorption peak which is located at around $655 \mathrm{~cm}^{-1}$ is arising from in-plane Al-O vibration rather than $\mathrm{Al}-\mathrm{O}-\mathrm{Si}$ vibration [35]. According to the literatures [34, 36], the presence of weak absorption peaks at about $669 \mathrm{~cm}^{-1}$ and $684 \mathrm{~cm}^{-1}$ is related to the vibrations modes of $\mathrm{Si}-\mathrm{O}$ band. Moreover, the absorption band at $694 \mathrm{~cm}^{-1}$ is corresponding to symmetrical bending vibrations of $\mathrm{Si}-\mathrm{O}$ whereas vibration band at $792 \mathrm{~cm}^{-1}$ can be attributed to symmetrical stretching vibrations of $\mathrm{Si}-\mathrm{O}$ [37]. Furthermore, the characteristic vibration at $937 \mathrm{~cm}^{-1}$ can be assigned to $\mathrm{O}-\mathrm{Si}-\mathrm{O}$ bond [38]. Besides, the absorption band at about $943 \mathrm{~cm}^{-1}$ can be associated with stretching mode of $\mathrm{Si}-\mathrm{OH}$ [39]. The infrared absorption band at $1118 \mathrm{~cm}^{-1}$ is attributed to the tetrahedral stretching vibration of silicon-apical oxygen (Si-O) [40]. Moreover, the absorption bands 
Fig. 4 SEM images of the $\mathrm{Al}$ thin films deposited on $\mathrm{SiO}_{2} /$ Si substrate at different RF Powers: a $100 \mathrm{~W}$, b $200 \mathrm{~W}$, c $300 \mathrm{~W}$ and d $400 \mathrm{~W}$

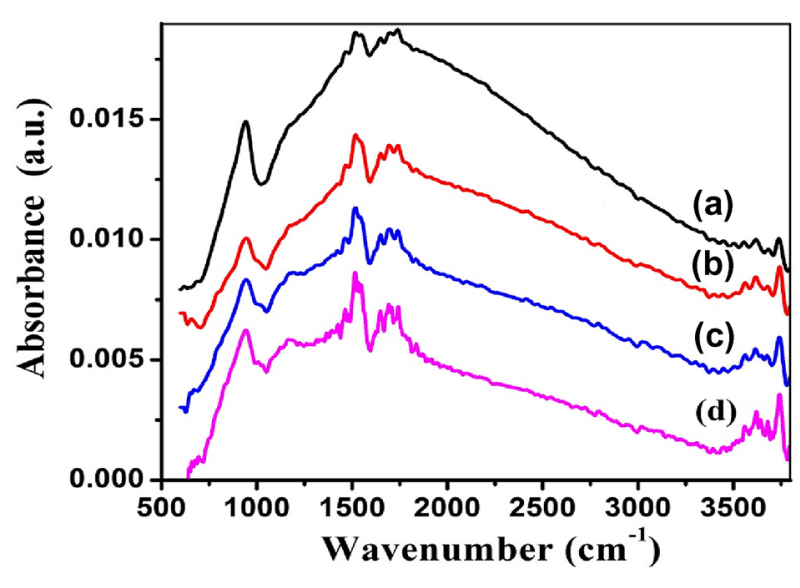

Fig. 5 FTIR spectra of the Al thin films deposited on $\mathrm{SiO}_{2} / \mathrm{Si}$ substrate at different RF powers: (a) $100 \mathrm{~W}$, (b) $200 \mathrm{~W}$, (c) $300 \mathrm{~W}$ and (d) $400 \mathrm{~W}$

at about $1164 \mathrm{~cm}^{-1}$ and $1649 \mathrm{~cm}^{-1}$ can be related to the antisymmetric stretching vibrations mode of Si-O-Si of silica and O-H deformation, respectively [41]. Furthermore, the bands in the range of $1300-1516 \mathrm{~cm}^{-1}$ are assigned to the Si-O-Si stretching bands of low "crystallinity" phases, mainly amorphous silica [38]. In addition, in the higher frequency region, the absorption bands at approximately $3554 \mathrm{~cm}^{-1}, 3616 \mathrm{~cm}^{-1}$ and $3741 \mathrm{~cm}^{-1}$ are attributed to the $\mathrm{OH}$ stretching modes of $\mathrm{Al}(\mathrm{OH}) \mathrm{Si}[42]$ and $(\mathrm{Al} \mathrm{Al})$ $\mathrm{O}-\mathrm{OH}$ [43] Si-OH groups, respectively. The observation of $\mathrm{OH}$ stretching modes in all the samples may be due to the presence of silicate in the substrate. Furthermore, the FTIR results show that the varying RF power affect the chemical structure of the deposited films [44].

The intensity of an absorption band in FTIR spectra depends on the number of the specific bonds present [45].

\section{Conclusions}

In this study, $\mathrm{Al}$ thin films were deposited on the $\mathrm{SiO}_{2} /$ Si substrates by RF magnetron sputtering system, and the influence of the RF power on the structure and surface morphology of the deposited films was investigated experimentally. The study of structural properties implicate that the sample deposited at $300 \mathrm{~W}$ has lower RMS roughness and smooth surface, this is because the kinetic energy of the incoming atoms, particles or ions, increases and led to enhances the lateral diffusion of the ions or particles. The results reveal that when the sputtering power was increased to $400 \mathrm{~W}$, the deposition particles did not have enough time to disperse over the substrate and clumped together to form larger grains, increasing surface roughness. It is concluded that increasing the sputtering power enhanced the crystallinity of the deposited films, while altering the sputtering power affected the chemical structure of the deposited films. This paper findings show that the RF power influences the characteristics of deposited films, and that by changing the sputtering power, the desired morphological structure and properties may be tuned. 
Funding Open access funding provided by Università degli Studi di Roma La Sapienza within the CRUI-CARE Agreement.

Open Access This article is licensed under a Creative Commons Attribution 4.0 International License, which permits use, sharing, adaptation, distribution and reproduction in any medium or format, as long as you give appropriate credit to the original author(s) and the source, provide a link to the Creative Commons licence, and indicate if changes were made. The images or other third party material in this article are included in the article's Creative Commons licence, unless indicated otherwise in a credit line to the material. If material is not included in the article's Creative Commons licence and your intended use is not permitted by statutory regulation or exceeds the permitted use, you will need to obtain permission directly from the copyright holder. To view a copy of this licence, visit http://creativecommons.org/licenses/by/4.0/.

\section{References}

1. K. Bordo, H. Rubahn, Effect of deposition rate on structure and surface morphology of thin evaporated al films on dielectrics and semiconductors. Mater. Sci. 18, 13 (2012). https://doi.org/ 10.5755/j01.ms. 18.4 .3088

2. F.M. Mwema, O.P. Oladijo, S.A. Akinlabi, E.T. Akinlabi, Properties of physically deposited thin aluminium film coatings: a review. Alloy. Compd. 747, 306 (2018). https://doi.org/10. 1016/j.jallcom.2018.03.006

3. S.B. Mansoor, B.S. Yilbas, Phonon transport in a curved aluminum thin film due to laser short pulse irradiation. Opt. Laser Technol. 101, 107 (2018)

4. G. Beck, S. Funk, Correlation between optical appearance and orientation of aluminum. Surf. Coat. Technol. 206, 2371 (2012)

5. G. Tan, D. Tang, D. Dastan, A. Jafari, Z. Shi, Q. Chu, J. Silva, $X$. Yin, Structures, morphological control, and antibacterial performance of tungsten oxide thin films. Ceram. Int. 47, 17153$17160(2021)$

6. G. Tan, D. Tang, D. Dastan, A. Jafari, J. Silva, X. Yin, Mater. Sci. Semicond. Process 122, 105506 (2021)

7. W. Zhang, X. Zhu, L. Liang, P. Yin, P. Xie, D. Dastan, K. Sun, R. Fan, Z. Shi, Significantly enhanced dielectric permittivity and low loss in epoxy composites incorporating $3 \mathrm{~d} \mathrm{~W}-\mathrm{WO}_{3} /$ $\mathrm{BaTiO}_{3}$ foams. J Mater Sci 56, 4254-4265 (2021)

8. Y. Jiao, Z. Huang, W. Hu, X. Li, Q. Yu, Y. Wang, Y. Zhou, D. Dastan, In-situ hybrid $\mathrm{Cr}_{3} \mathrm{C}_{2}$ and $\gamma^{\prime}-\mathrm{Ni}_{3}(\mathrm{Al}, \mathrm{Cr})$ strengthened $\mathrm{Ni}$ matrix composites: microstructure and enhanced properties. Mater. Sci. Eng. A 820(2021), 141524 (2021)

9. K. Shan, Z. Yi, X. Yin, D. Dastan, S. Dadkhah, B. Coates, H. Garmestani, Mixed conductivities of A-site deficient Y, Cr-doubly doped $\mathrm{SrTiO}_{3}$ as novel dense diffusion barrier and temperature-independent limiting current oxygen sensors. Adv. Powder Technol. 31, 4657-4664 (2020)

10. E.A. Esfahani, H. Salimijazi, M.A. Golozar, J. Mostaghimi, L. Pershin, A comprehensive review of corrosion resistance of thermally- sprayed and thermally-diffused protective coatings on steel structures. Therm. Spray. Techn. 21, 1195 (2012). https://doi.org/10.1007/s11666-019-00855-3

11. M.G. Faraj, K. Ibrahim, Investigation of the structural properties of thermally evaporated aluminium thin films on different polymer substrates. Int. J. Thin. Film. Sci. Tech. 4, 17 (2015). https://doi.org/10.12785/ijtfst/040106

12. C. Jaing, J. Opt. Quant. Electron 28, 1583 (1996)

13. H. Takatsuji, T. Arai, Pinholes in Al thin films: their effects on TFT characteristics and a taguchi method analysis of their origins. Vacuum 59, 606 (2000). https://doi.org/10.1016/S0042207X(00)00323-7

14. C.W. Hollars, R.C. Dunn, Evaluation of thermal evaporation conditions used in coating aluminum on near-field fiber-optic probes. Rev. Sci. Instrum. 69, 1747 (1998). https://doi.org/10. 1063/1.1148836

15. H.Shinohara, H. Morooka, I. Ikeo, A. Takenouchi, S. Nakajima,Y. Arai, Solar Cell and Method for Producing Electrode for Solar Cell, United States Patent US005891264A, 1999.

16. A.T. Voutsas, Y. Hibino, R. Pethe, E. Demaray, Structure engineering for hillock-free pure aluminum sputter deposition for gate and source line fabrication in active-matrix liquid crystal displays. Vac. Sci. Technol. A 16, 2668 (1998). https://doi.org/ 10.1116/1.581398

17. G. Kaune, E. Metwalli, R. Meier, V. Körstgens, K. Schlage, S. Couet, R. Röhlsberger, S.V. Roth, P. Müller-Buschbaum, Growth and Morphology of Sputtered Aluminum Thin Films on P3HT Surfaces. ACS Appl. Mater. Interfaces 3, 1055 (2011)

18. X. Yu-Qing, L. Xing-Cun, C. Qiang, L. Wen-Wen, Z. Qiao, S. Li-Jun, L. Zhong-Wei, W. Zheng-Duo, Y. Li-Zhen, Characteristics and properties of metal aluminum thin films prepared by electron cyclotron resonance plasma-assisted atomic layer deposition technology. Chin. Phys. B 21, 078105 (2012)

19. M.J. Lee, T.I. Lee, J. Lim, J. Bang, W. Lee, T. Lee, J.M. Myoung, Effect of the deposition temperature and a hydrogen post-annealing treatment on the structural, electrical, and optical properties of Ga-doped $\mathrm{ZnO}$ films. Electron. Mater. Lett. 5, 127 (2009). https://doi.org/10.3365/eml.2009.09.127

20. H.W. Wu, R.Y. Yang, Ch.M. Hsiung, Ch.H. Chu, Influence of sintering temperatures of ceramic targets on microstructures and photoelectric properties of titanium-doped $\mathrm{ZnO}$ nano-films. Mater. Sci.: Mater. Electron. 24, 166 (2013). https://doi.org/10. 1007/s10854-016-6104-y

21. H. Khachatryan, S.N. Lee, K.B. Kim, H.K. Kim, M.J. Kim, Al thin film: the effect of substrate type on $\mathrm{Al}$ film formation and morphology. Phys. Chem. Solids 122, 109 (2018). https://doi. org/10.1016/j.jpcs.2018.06.018

22. N. Dhar, P. Chelvanathan, M. Zaman, K. Sopian, N. Amin, An investigation on structural and electrical properties of rf-sputtered molybdenum thin film deposited on different substrates. Energy Procedia 33, 186 (2013). https://doi.org/10.1016/j.egypro.2013.05.057

23. H. Mahdhi, Z.B. Ayadi, J.L. Gauffier, K. Djessas, S. Alaya, Influence of sputtering power on the properties of thin layers of GZO for photovoltaic applications. J. Mater. Sci. Mater. El. 26, 3336 (2015). https://doi.org/10.1007/s10854-015-2836-3

24. R. Murugan, G. Vijayaprasath, T. Mahalingam, Y. Hayakawa, G. Ravi, Effect of rf power on the properties of magnetron sputtered $\mathrm{CeO} 2$ thin films. J. Mater. Sci. Mater. El. 26, 2800 (2015). https://doi.org/10.1007/s10854-015-2761-5

25. Y.J. Zhao, D.Y. Jiang, M. Zhao, R. Deng, J.M. Qin, S. Gao, Q.C. Liang, J.X. Zhao, Effects of power on properties of $\mathrm{ZnO}$ thin films grown by radio frequency magnetron sputtering. Appl. Surf. Sci. 266, 440 (2013). https://doi.org/10.1016/j.apsusc. 2012.12.055

26. Zh. Chen, W. Tian, X. Zhang, Y. Wang, Effect of deposition parameters on surface roughness and consequent electromagnetic performance of capacitive RF MEMS switches: a review. Micromechanics Microengineering 27, 113003 (2017). https://doi.org/ 10.1088/1361-6439/aa8917

27. A. Mallikarjuna Reddy, A. Sivasankar Reddy, K.S. Lee, P. Sreedhara Reddy, Growth and characterization of $\mathrm{NiO}$ thin films prepared by dc reactive magnetron sputtering. Solid State Sc. 13, 314(2011).https://doi.org/10.1016/j.solidstatesciences.2010.11. 019 
28. E. Vaghri, Z. Khalaj, M. Ghoranneviss, M. Borghei, Characterization of diamond: like carbon films synthesized by DC-plasma enhanced chemical vapor deposition. Fusion Energ 30, 447 (2011). https://doi.org/10.1007/s10894-011-9406-3

29. J. Eskusson, R. Jaaniso, E. Lust, Synthesis of DLC films by PLD from liquid target and dependence of film properties on the synthesis conditions. Appl. Phys. A. 93, 745 (2008). https://doi.org/ 10.1007/s00339-008-4706-9

30. V. Bhatt, S. Chandra, Silicon dioxide films by RF sputtering for microelectronic and MEMS applications. J. Micromech. Microeng 17, 1066 (2007). https://doi.org/10.1088/0960-1317/17/5/029

31. A. Kale, R.S. Brusa, A. Miotello, Structural and electrical properties of AlN films deposited using reactive RF magnetron sputtering for solar concentrator application. Appl. Surf. Sci. 258, 3450 (2012). https://doi.org/10.1016/j.apsusc.2011.11.095

32. K. Wasa, S. Hayakawa, Handbook of Sputter Deposition Technology (Noyes Publications, New Jersey, 1992)

33. F.M. Mwema, O.P. Oladijo, E.T. Akinlabi, Mater. Today Proc. 5(9/3), 20464 (2018)

34. A. Gupta, V. Amitabh, B. Kumari, B. Mishra, FTIR and XRPD studies for the mineralogical composition of jharkhand bentonit. Res. J. Pharm. Biol. Chem. Sci. 4, 361 (2013)

35. J. Madejova, P. Komadel, Baseline studies of the clay minerals society source clays: infrared methods. Clays Clay Mineral 49, 410 (2001). https://doi.org/10.1346/CCMN.2001.0490508

36. D.M. Jenkins, Empirical study of the infrared lattice vibrations (1100-350 cm-1) of phlogopite. Phys. Chem. Mineral 16, 408 (1989). https://doi.org/10.1007/BF00199563

37. A. Paula dos Santos Pereira, M. Henrique Prado da Silva, E. Pereira Lima Júnior, A. dos Santos Paula, F. James Tommasini, Processing and Characterization of PET Composites Reinforced With Geopolymer Concrete Waste. Mater. Res. 20, 411 (2017). https://doi.org/10.1590/1980-5373-mr-2017-0734.

38. T. Ahmad, K. Ahmad, M. Alam, Characterization and constructive utilization of sludge produced in clari-flocculation unit of water treatment plant. Mater. Res. Express 5, 035511 (2018). https://doi. org/10.1088/2053-1591/aab23a

39. T. Hurma, Optical Vibrational And Morphological Properties Of S-Co3o4 Nanostructured Thin Film. Sci. and Technology A, Appl. Sci. and Eng. 18, 388 (2017). https://doi.org/10.18038/aubtda. 295720.

40. M. Catauro, F. Papale, F. Bollino, S. Piccolella, S. Marciano, P. Nocera, S. Pacifico, Silica/quercetin sol-gel hybrids as antioxidant dental implant materials. Sci. Technol. Adv. Mater. 16, 035001 (2015). https://doi.org/10.1088/1468-6996/16/3/035001

41. K. Kitajima, N. Takusagawa, Effects of tetrahedral isomorphic substitution on the IR spectra of synthetic fluorine micas. Clay Miner. 25, 235 (1990). https://doi.org/10.1180/claymin.1990. 025.2.08

42. M. Diko, G. Ekosse, J. Ogola, Fourier transform infrared spectroscopy and thermal analyses of kaolinitic clays from south africa and cameroon. Acta Geodyn. Geomater 13, 149 (2016). https:// doi.org/10.13168/AGG.2015.0052

43. J. Antonio Cecilia, L. Pardo, M. Pozo, E. Bellido, F. Franco. Microwave-Assisted Acid Activation of Clays Composed of 2:1 Clay Minerals: A Comparative Study. Minerals 8, 376 (2018). https://doi.org/10.3390/min8090376.

44. N. Tabatabaii, D. Dorranian, Effect of fluence on carbon nanostructures produced by laser ablation in liquid nitrogen. Appl. Phys. A 122, 558 (2016)

45. M. Yang, M. Ye, H. Han, G. Ren, L. Han, Zh. Zhang, Spectroscopy (2018). https://doi.org/10.1155/2018/6958260

Publisher's Note Springer Nature remains neutral with regard to jurisdictional claims in published maps and institutional affiliations. 